ISSN 0258-7122

Bangladesh J. Agril. Res. 36(1) : 13-20, March 2011

\title{
TIME AND AGE SPECIFIC MATING SUCCESS OF BUMBLEBEE (Bombus terrestris L.) REARED AT DIFFERENT PHOTOPERIODIC REGIMES
}

\begin{abstract}
M. R. AMIN ${ }^{1}$ AND V. J. KWON ${ }^{2}$
Abstract

In this study, mating success of bumblebee, Bombus terrestris was recorded by five age groups of queens viz. 3, 5, 7, 9, and 11 days old, and the males were two days older than each age group of queens. Newly emerged males and queens were collected from different colonies and they were reared under four photoperiods e.g., L0:D24, L8:D16, L16:D8, and L24:D0 for observing the mating activities. Three days old queens with 5 days old males showed the lowest mating success at all photoperiodic regimes. Most of the couples mated within first 15 minutes of pairing and mating success increased with increasing duration of mating exposure. At the L0:D24 and L8:D16 photoperiodic regimes 9 days old queens with 11 days old males had the highest mating success (65.4 \pm 3.3 and $85.0 \pm 2.3 \%$, respectively) whereas at L16:D8 and L24:D0 photoperiodic conditions, the highest mating success occurred when 7 days old queens paired with 9 days old males (92.1 \pm 1.7 and $76.3 \pm 3.2 \%$, respectively). These results indicate that rearing of bees at different light regimes, age of bees and duration of mating exposure had significant effect on mating success of $B$. terrestris.
\end{abstract}

Keywords: Age, Bombus terrestris, mating, photoperiod, time.

\section{Introduction}

Bumblebees, Bombus terrestris L. (Hymenoptera: Apidae) are primitively eusocial bees which have been shipped throughout the world in vast numbers for pollinaton of glass house crops (Goka et al., 2001; Velthuis, 2002). Inseminated queens emerge from hibernation at the end of spring and the colony is founded by a single queen. At the end of summer, colonies produce males and queens that mate and the young queens leave the nest, and fly for several weeks in day light before they hibernate into the ground (Tasei and Aupinel, 1994). Now a days, mass rearing of bumblebees are very common, especially $B$. terrestris is extensively used for pollination. For commercial rearing, it is necessary to arrange mating of newly emerged queens and males. Readiness of mating depends on the sexual maturity of male and perfect overian development of queen. Halliday (1983) reported that the successful mating is the result of numerous interacting factors including male and female choice, male courtship behaviour, female responses to courtship, female

\footnotetext{
${ }^{1}$ Department of Entomology, Hajee Mohammad Danesh Science and Technology University, Dinajpur, Bangladesh, ${ }^{2}$ Department of Agricultural Biology, Kyungpook National University, Daegu, Korea.
} 
reproductive or motivational status and mating competition. Bergstrom (1981) reported that volatile secretions from the cephalic labial glands of bumblebee males and the mandibular glands of queens played a significant role in producing sex pheromone which had great role for mating.

Philogene and McNeil (1984) stated that sperm migration and mating of insects was influenced by artificial light. Mating activity of the fruit fly, Drosophila mercatorum shows the daily rhythms of the mating activity under 12:12 light-dark (LD) cycles and several Drosophila species show the daily rhythms of male courtship under different LD cycles (Sakai and Ishida, 2001). Circadian rhythms also influence behaviour by transmitting intracellular signals to organize cellular metabolism, and intercellular signals to organize multicellular physiology and behaviour (Jackson et al., 1998). Duchateau (1985) reported results on the impact of temperature, light and time of day for bumblebee mating. Photoperiods are positively correlateld with temperatures which change the timing of the life-history events of insects (Ishihara, 2000; Zhou, 2001). Therefore, this study was designed in confined conditions with altering photoperiods e.g., L0:D24, L8:D16, L16:D8, and L24:D0 to quantify whether light regimes have any stimulating effect on the different ages of bees for their mating success within different time frame.

\section{Materials and Method}

Artificially hibernated bumblebee queens were collected from the mass rearing system of the Department of Agricultural Biology, Kyungpook National University, Daegu, Korea. The study was conducted in the Laboratory of this Department during March 2004 to December 2006. B. terrestris colonies were developed at $28^{\circ} \mathrm{C}$ and $60 \% \mathrm{RH}$ providing ad. libitum pollen of Actinidia arguta (Plench) and sugar solutions (1.5:1, w/v) as a diet. After emergence of new sexuals, queens were reared in small transparent plastic boxes measuring $16 \mathrm{x}$ $\mathrm{x} 7 \mathrm{~cm}$. Ten queens were kept in each box and provided with fresh pollen in a small petridish and sugar solutions $(1.5: 1, \mathrm{w} / \mathrm{v})$ in a perforated tube. Males were reared in flight cages $(40 \times 30 \times 30 \mathrm{~cm}$ ) which had illumination facility. Fifty males were put in each cage which was supplied with fresh pollen and sugar solutions $(1.5: 1, \mathrm{w} / \mathrm{v})$. The boxes of queens and cages of males were held in four separate rooms maintained at $25^{\circ} \mathrm{C}, 50 \% \mathrm{RH}$ and photoperiodic regimes of L0:D24, L8:D16, L16:D8, and L24:D0 conditions until mating time. Photoperiodic treatments were scheduled with fluorescent white (L36/18-860, $300 \mathrm{~Hz}, \lambda=460 \mathrm{~nm}$ ) light at an intensity of 700 lux on the floor of the male cages and queen boxes. The intensity of light was measured with a digital lux meter and the photophase was regulated with timer. The mating success results were observed in 40 x 40 x $60 \mathrm{~cm}$ plastic cages. Sugar solutions and fresh pollen were supplied inside the cages. Mating was recorded in a room maintained at $25^{\circ} \mathrm{C}$ and $50 \% \mathrm{RH}$. During mating, the cages were illuminated with $200 \mathrm{~W}$ 
mercury bulbs (GGY200, $60 \mathrm{~Hz}, \lambda=580 \mathrm{~nm}$ ) which were set $0.5 \mathrm{~m}$ above the mating cages. The intensity of light on the floor of the mating cages was 2300 lux. In each photoperiodic regime, five different age groups of queens were observed, having 3, 5, 7, 9, and 11 days old. The males were 2 days older than the queens in their respective age groups. Twenty queens and 40 males were released in each replication. Each age group reared in the same photoperiodic regime was replicated 12 times. The occurrence of copulation was recorded at 15 , 30, and 45 minutes after pairing. Percent mating data were analyzed by analysis of variance (ANOVA) after arc-sine transformation. The mean values were then separated by Duncan's multiple range test (DMRT) and the standard errors (SE) have been shown on the figures. All the analyses were performed by SPSS Inc (PASW Statistics 17).

\section{Results and Discussion}

Fig. 1 shows the mating success of $B$. terrestris at 15 minutes exposure and entrained by 3, 5, 7, 9, and 11 days old queens reared at L0:D24, L8:D16, L16:D8, and L24:D0 photoperiodic conditions. Mating success data (Fig. 1a) of the bees reared at L0:D24 condition shows significant differences $\left(\mathrm{F}_{4.59}, 26.7, \mathrm{p}<0.001\right)$. Among the age groups, 3 days old queens showed the lowest mating success (29.2 $\pm 3.0 \%$ ), whereas the highest mating success $(60.4 \pm 2.6 \%)$ was attained by the 9 days old queens. Fig. lb shows that the mating success by the bees reared at L8:D16 condition revealed significant variations $\left(\mathrm{F}_{4.59},=57.9, \mathrm{p}<0.001\right)$.

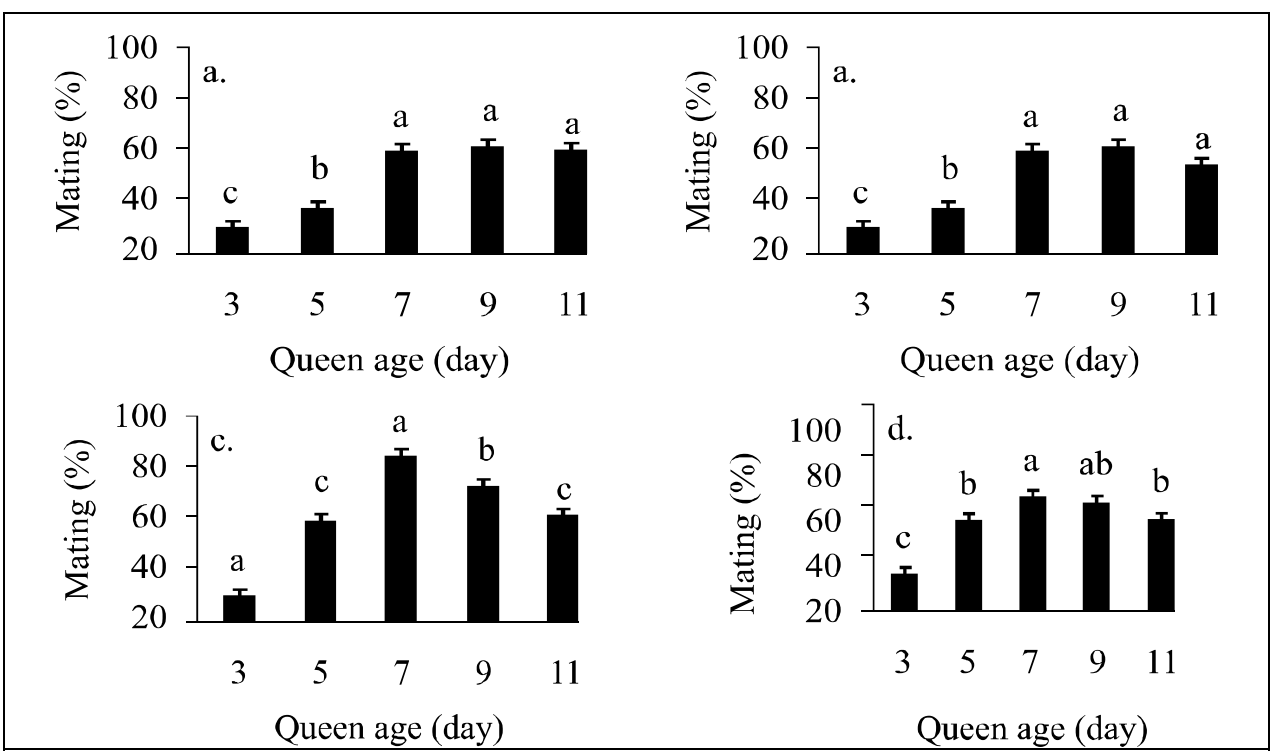

Fig. 1. Effect of age on the mating success (mean $\pm \mathrm{SE} \%$ ) of $B$. terrestris within 15 minutes exposure when reared at a) L0:D24, b) L8:D16, c) L16:D8, and d) L24:D0 condition. Bars with no common letter (s) are significantly different (DMRT, $\mathrm{p} \leq 0.05$ ). 
The highest mating success ( $80.4 \pm 2.5 \%)$ was recorded by 7 days old queens and the lowest result $(33.3 \pm 2.7 \%)$ was found by the 3 days old queens. There were significant differences among the mating success rates of the bees reared at L16:D8 condition $\left(F_{4,59}=70.5, p<0.001\right)$. The highest $(85.0 \pm 2.2 \%)$ and lowest $(30.0 \pm 2.5 \%)$ mating success rates were performed by 7 and 3 days old queens, respectively (Fig. lc). The different age groups of bees reared at L24:D0 condition showed significant variation in their mating success rates $\left(\mathrm{F}_{4.59}=22.4\right.$, $\mathrm{p}<0.001$ ). The observed mating rates varied from $36.3 \pm 2.9$ to $70.0 \pm 2.8 \%$ and 7 days old queens showed the highest mating success.

Mating success of B. terrestris at 30 minutes exposure is presented in Fig. 2. Mating data of the bees reared in L0:D24 condition (Fig. 2a) showed significant differences $\left(\mathrm{F}_{4.59}=25.1, \mathrm{p}<0.001\right)$ and the highest $(62.9 \pm 2.7 \%)$ and lowest $(30.4+2.7 \%)$ mating success rates were recorded by 9 and 3 days old queens, respectively. Fig. $2 \mathrm{~b}$ shows that the mating success of the bees that were reared at L8:D16 condition revealed significant variations $\left(\mathrm{F}_{4.59}=65.4, \mathrm{p}<0.001\right)$ on the basis of their age groups. The highest $(82.9 \pm 2.7 \%)$ and lowest $(35.0 \pm 2.4)$ mating success rates were recorded by 7 and 3 days old queens, respectively.

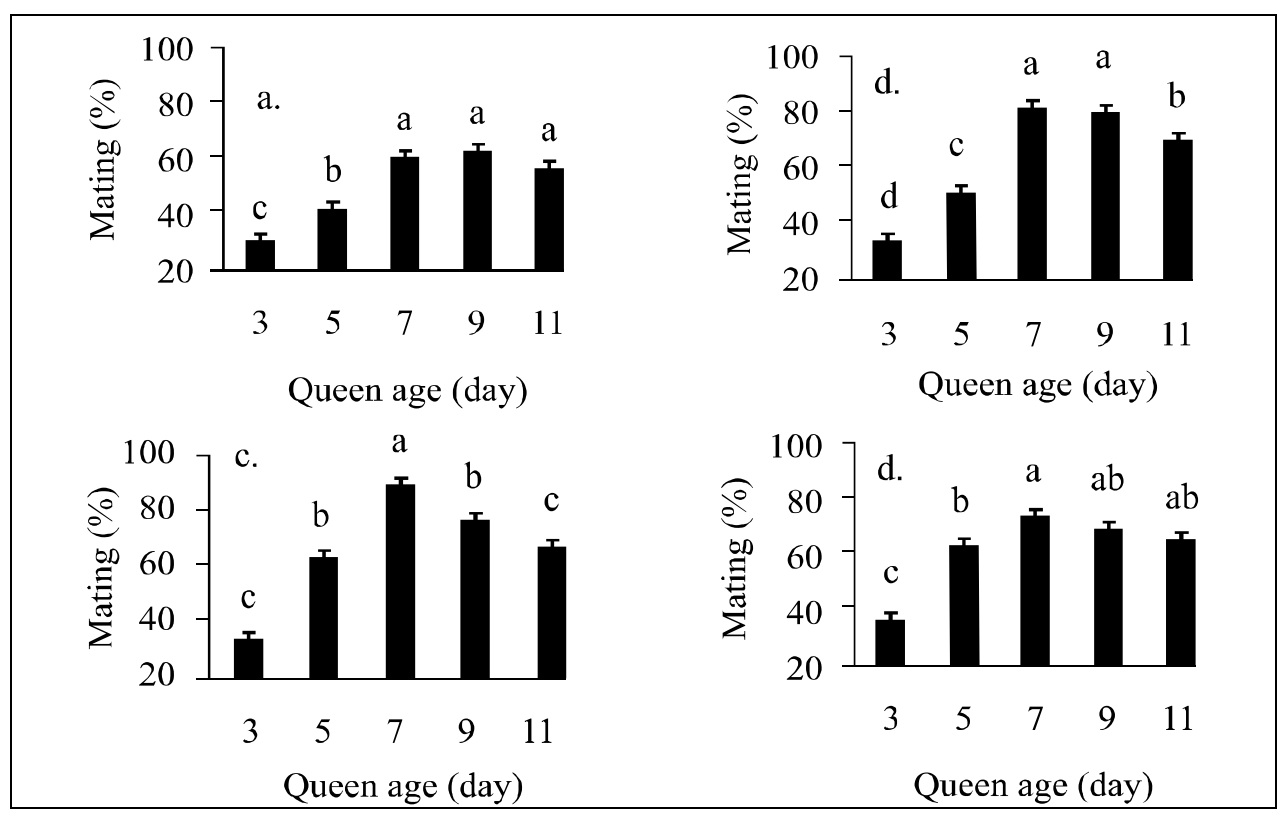

Fig. 2. Effect of age on the mating success (mean $\pm \mathrm{SE} \%$ ) of $\mathrm{B}$. terrestris within 30 minutes exposure when reared at a) LO:D24, b) L8:D16, c) L16:D8 and d) L24:DO condition. Bars with no common letter (s) are significantly different $(\mathrm{DMRT}, \mathrm{p} \leq 0.05)$

The age groups of bees had significant effect $\left(\mathrm{F}_{4.59}=64.3, \mathrm{p}<0.001\right)$ on the mating success when they were reared at L16:D8 condition (Fig. 2c), and their 
success rates ranged from $33.3 \pm 2.7$ to $89.6 \pm 1.3 \%$. Mating success rates by different age groups of bees reared at L24: DO condition also showed significant differences $\left(\mathrm{F}_{4.59}=22.9, \mathrm{p}<0.001\right)$ and the performed matings differed from $38.3 \pm 2.8$ to $74.2 \pm 3.2 \%$.

Mating success results of the different age groups of bees after 45 minutes of exposure is presented in Fig. 3. Fig. 3a shows that the mating success of the bees reared at L0:D24 condition were significantly different $\left(\mathrm{F}_{4.59}=22.7, \mathrm{p}<0.001\right)$. The highest $(65.4 \pm 3.3 \%)$ and lowest $(32.9 \pm 2.7 \%)$ mating success rates were attained by 9 and 3 days old queens, respectively. Fig. 3b shows that there was significant difference $\left(\mathrm{F}_{4.59}=65.7, \mathrm{p}<0.001\right)$ among the mating success of the bees reared at L8:D16 condition. The recorded mating success rates ranged from $36.3 * 2.6$ to $85.0 \pm 2.3 \%$. The mating success rates of the different age groups of bees reared at L16:D8 condition varied from $35.4 \pm 2.7 \%$ to $92.1 \pm 1.7 \%$ which were significantly different $\left(\mathrm{F}_{4.59}=71.3, \mathrm{p}<0.001\right)$. The different age groups of bees reared at L24:D0 condition showed significant differences in their mating success $\left(\mathrm{F}_{4.59}=27.5, \mathrm{p}<0.001\right)$. The observed mating success rates varied from $39.2 \pm 3.0$ to $76.3 \pm 3.2 \%$ and 7 days old quees showed the highest mating success.

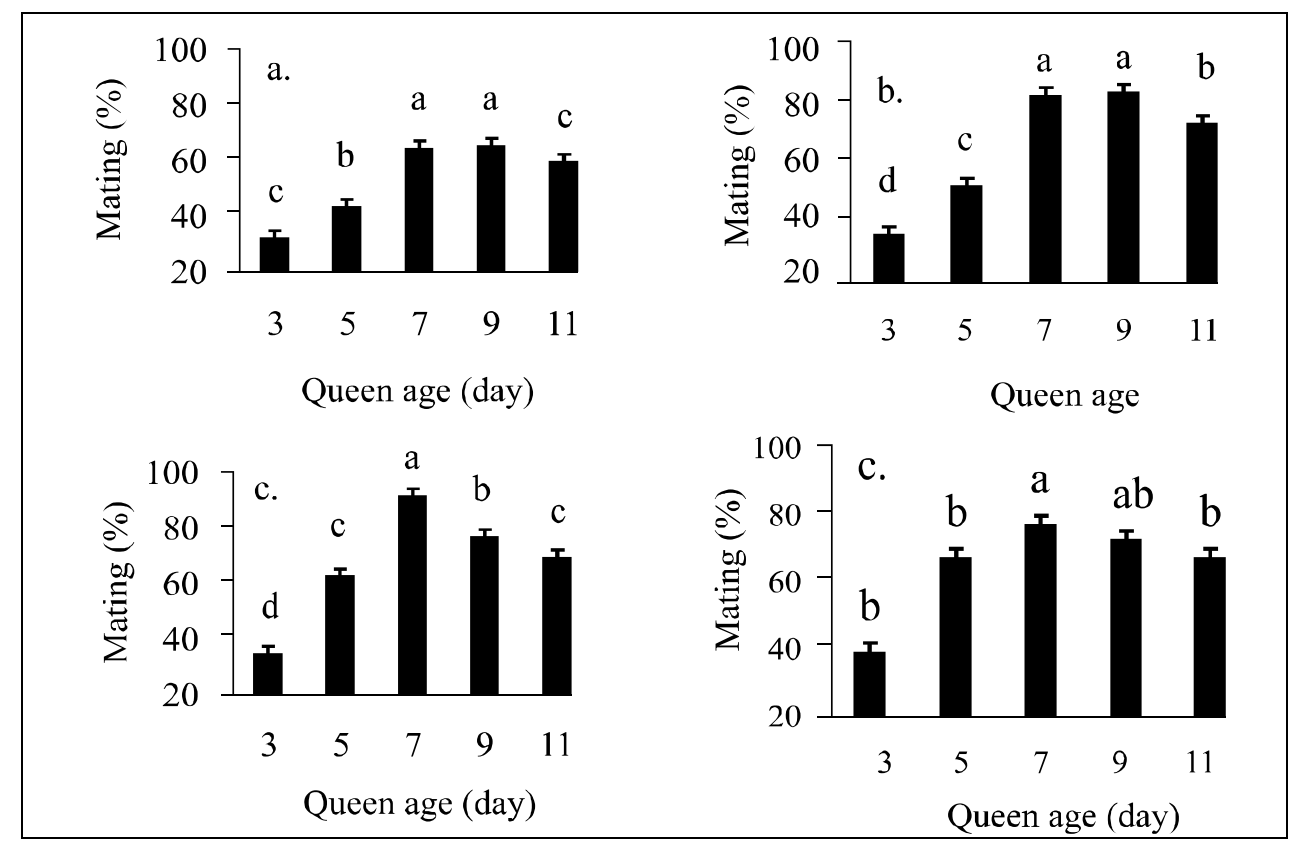

Fig. 3. Effect of age on the mating success (mean \pm SE\%) of $B$. terrestris within 45 minutes exposure when reared at a) L0:D24, b) L8:D16, c) L16:D8, and d) L24:D0 condition. Bars with no common letter (s) are significantly different (DMRT, $\mathrm{p} \leq 0.05)$. 
Different light regimes, age of bees, and duration of mating exposure showed a strong effect on the mating success of $B$. terrestris. The highest mating success (92.1 $\pm 1.7 \%)$ resulted at L16:D8 pre-mating conditions when queens were 7 days old and males 9 days old. These results were in agreement with Tasei et al. (1998) who reported that 6 days old queens were effective for mating. They also stated that the age groups for mating ranging between 6 and 27 days for males and between 2 and 11 days for queens, and showed that the chances of the queens mating dropped dramatically after 11 days. Duvoisin et al. (1999) found that the mean value of the age of mating was 6.1 days for queens and 12.1 days for males. It was suggested by Gretenkord (1997) that the readiness of queen to mate seemed to be the greatest at around 6 days of age. Our present study is in agreement of Duchateau (1985) who reported that aging queens become gradually less receptive to mating. She suggested that this might be due to a decrease in queen's sensitivity to the male pheromones. She also suggested that temperature, light or time of the day are important factors influencing mating success. Jung et al. (2001) recorded the highest mating rate of $B$. ardens by 7 day old queens. They found that $80 \%$ of queens mated within 4 hours at L14:D10 photoperiodic regime. Lee et al. (2002) conducted a study of bumblebee, $B$. ignitus mating in the field and in indoor conditions. They observed that the mating success in the field were $80 \%$, and $60 \%$ in indoors. Our study suggests that 7 days old queens with 9 days old males living in long day cycle or 9 days old queens with 11 days old males reared in short day cycle have significantly higher success rates of mating compared to bumblebees of the same age, kept in constant light or dark cycle.

Light regimes influence the sexual maturity and pheromone production of black cutworm moth (Gemeno and Haynes, 2001), ovarian maturation of Locusta (Tanaka et al., 1993) and reduction of pre-mating period in Heteroptera (Wang and Millar, 2000; Hel et al., 2004). Barth et al. (1997) reared Drosophila melanogaster at different photoperiodic regimes and found that light regimes had a positive effect on mating. Photoperiod had a significant role in the mating success in moths (Seth et al., 2002). So far, the discussion had concentrated the effects of light regimes on the mating behaviour. The present results showed that mating status of $B$. terrestris was affected by the combined effect of photoperiodism, the age of bees and exposure time. Queens of 7 days old and 9 days old males reared at long day, and queens of 9 days old and 11 days old males reared at short day photoperiodic regimes reached the best receptivity for mating. All the age groups of bees reared at different photoperiodic regimes showed higher receptivity for mating within first 15 minutes of exposure and mating success slightly increased with increasing exposure time. So, the findings of this study will contribute information to the commercial breeders for effective rearing of bumblebees. 


\section{References}

Barth, M., H. V. B. Hirsch and M. Heisenberg. 1997. Rearing in different light regimes affects cdurtship behaviour in Drosophila melanogaster. Anim. Behav. 53: 25-38.

Bergstrom, G. 1981. Chemical composition, similarity and dissimilarity in volatile secretions: examples of indications of biological function. Les mediateurs chemiques agissant sur le comportement des insects, Les colloques de I'NRA. pp. 289-296.

Duchateau, M. J. 1985. Analysis of some methods for rearing bumblebee colonies. Apidologie 16: 225-227.

Duvoisin, N., B. Baer and P. Schmid-Hempel. 1999. Sperm transfer and male competition in bumblebees. Anim. Behav. 58: 743-749.

Gemeno, C. and K. F. Haynes. 2001. Impact of photoperiod on the sexual behaviour of black cutworm moth (Lepidoptera: Noctuidae). Environ. Entomol. 30: 189-195.

Goka. K., K. Okabe, Y. Yoneda and S. Niwa. 2001. Bumblebee commercialization will cause worldwide migration of parasitic mites. Mol. Ecol. 10: 2095-2099

Gretenkord, C. 1997. Laborzucht der Dunklen Erdhummel Bombus terrestris L. (Hymenoptera: Apidae) und toxikologische Untersuchungen unter Laborund Halbfreilandbedingungen, Ph. D. Thesis, Rheinischen FriedrichWilhelms Univ. Bonn.

Halliday, T. R. 1983. The study of mate choice. In: Mate Choice (ed. Bateson, P.), Cambridge Univ. Press, Cambridge. pp. 3-32.

Hel, X. Z., Q. Wang and A. Carpenter. 2004. Effect of day length on development and reproductive diapause in Nysius huttoni White (Heteroptera: Lygaeidae). J. Appl. Ent. 128: 528-532.

Ishihara, M. 2000. Effect of variation in photoperiodic response on diapause induction and development time in willow leaf beetle, Plagiodera versicolora. Ent. Exp. Appl. 96: 27-32.

Jackson, F. R., X. Zhang and G. P. McNeil. 1998. Oscillating molecules and circadian clock output mechanisms. Mole. Physiol. 3: 38 1-385.

Jung, J. K., Y. I. Mah and J. S. Kim. 2001. Mating rate of Bombus ardens (Hymenoptera: Apidae) queens with day time and age. Korean J Apic. 16: 37-44.

Lee, S., Y. Mah., H. Yoon., I. Park and T. Bae. 2002. The mating in the field and the indoor condition of Korea indigenous bumblebee, Bombus ignitus queen. Korean $J$. Apic. 17: 103-1 12.

Philogene, B. and J. N. McNeil. 1984. The influence of light on the nondiapause related aspects of development and reproduction in insects. Photochem. Photobiol. 40: 753-761.

Sakai, T. and N. Ishida. 2001. Circadian rhythms of female mating activity governed by clock genes in Drosophila. Proc. Natl. Acad. Sci. 98: 9221-9225.

Seth, R. K., D. K. Rao and S. E. Reynolds. 2002. Movement of spermatozoa in the reproductive tract of adult male, Spodoptera litura: daily rhythm of sperm descent and the effect of light regime on male reproduction. J. Insect Physiol. 48: 119-13 1. 
Tanaka, S., T. Hakomori and E. Hasegawa. 1993. Effect of day length and hopper density on reproductive traits in a Japanese population of the migratory locust, Locusta migratoria L. J. Insect Physiol. 39: 57 1-580.

Tasei, J. N. and P. Aupinel. 1994. Effect of photoperiodic regimes on the oviposition of artificially overwintered Bombus terrestris L. queens and the production of sexuals. J. Apic. Res. 33: 27-33.

Tasei, J. N., C. Moinard, L. Moreau, B. Himpens and S. Guyonnaud. 1998. Relationship between aging, mating and sperm production in captive Bombus terrestris. J. Apic. Res. 37: 107-113.

Velthuis, H. H. W. 2002. The historical background of the domestication of the bumblebee, Bombus terrestris, and its introduction in agriculture: Pollinating beesthe conservation link between agriculture and nature (ed. Kevan P. and I. Fonsesa), Ministry of Environment, Brazil, pp 177-184.

Wang, Q. and J. G. Millar. 2000. Mating behaviour and evidence for male produced sex pheromones in Leptoglossus clypealis (Heteroptera: Coreidae). Ann. Ent. Soc. Am. 93: $972-976$

Zhou, H. Z. 2001. Reproduction of Lagria hirta (Coleoptera: Lagriidae) and its lifehistory trait correlation. Environ. Entomol. 30: 686-691. 